\title{
Malnutrition and anthropometric measurements among elderly people with cardiovascular diseases
}

\author{
Z. Orang ${ }^{1}$, Z. Mazloom², ${ }^{\text {N. Hejazi }}{ }^{2}$
}

\begin{abstract}
${ }^{1}$ Department of Nutrition, School of Health, Yazd University of Medical Sciences, Yazd, Iran
${ }^{2}$ Nutrition and Food Sciences Research Center, Department of Clinical Nutrition, School of Nutrition and Food Sciences, Shiraz University of Medical Sciences, Shiraz, Iran

Corresponding address: Najmeh Hejazi, Department of Clinical Nutrition, School of Nutrition and Food Sciences, Razi Blvd., Shiraz, Iran

Tel: +98-71-37251005, Email: nhejazi@sums.ac.ir

Received: 3 Aug 2017; Accepted: 29 Nov 2017
\end{abstract}

\section{* Abstract}

Background: Aging is accompanied by physiologic changes that can negatively impact nutritional status. Progressive under nutrition during aging is associated with early death. Some food avoidance could complicate nutritional status during chronic diseases in elderly people.

Objective: The aim of this study was to compare malnutrition among elderly people with and without cardiovascular diseases (CVDs).

Method: This case-control study was conducted on 64 healthy elder subjects (as a control group) and 64 elderly patients with CVDs (as a case group) in Shiraz (2017). Demographic and mini nutritional assessment (MNA) questionnaires were completed for each participant. Anthropometric data (weight, BMI, waist, hip, arm and calf circumferences) were measured.

Findings: Malnutrition distribution was significantly different between two groups based on MNA score $(\mathrm{P}<0.001)$ and $48(75 \%)$ of healthy elderly participants and $18(28.1 \%)$ of patients weren't malnourished. Risk of malnutrition was 35 (54.7\%) and 16 (25\%) in unhealthy and healthy groups respectively. Only 11 (17.2\%) of elderly patients with CVDs were malnourished.

Conclusion: Malnutrition rate increased in elderly patients with CVDs compared to healthy old group. It seems that food avoidance of the disease is the cause of higher malnutrition rate. Attention to the balance and adequacy of macronutrient intake in a personal diet of CVDs patients can be a method to prevent progression of malnutrition in old patients.

Keywords: Malnutrition, Anthropometry, Elderly, Cardiovascular diseases

Citation: Orang Z, Mazloom Z, Hejazi N. Malnutrition and anthropometric measurements among elderly people with cardiovascular disease. J Qazvin Univ Med Sci 2018; 21 (6): 46-54. 


\title{
سوءتغذيه و شاخصهاى تنسنجى در سالمندان مبتلا به بيمارىهاى قلبى - عروقى
}

\author{
زهرا اورنغَ'، دكتر زهره مظلوم'، دكتر نجمه حجازى"
}

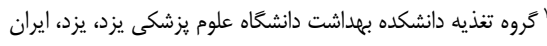

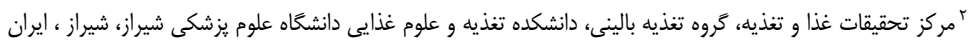

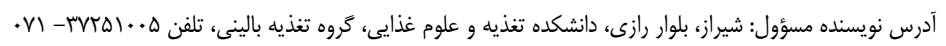

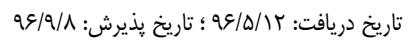

زمينه: سالمندى با تغييرات فيزيولوزيكى همراه است كه مى تواند بر وضعيت تغذيه فرد اثرات منفى بر جاى كَذارد. ايـن در حـالى اسـت كـه برخى

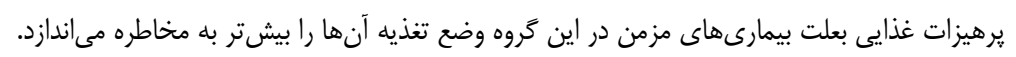

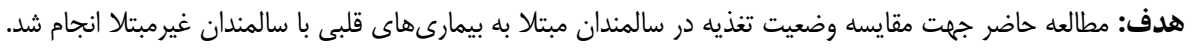

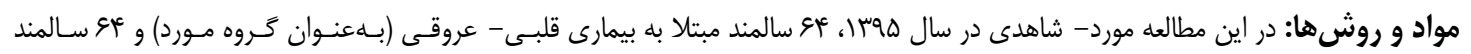

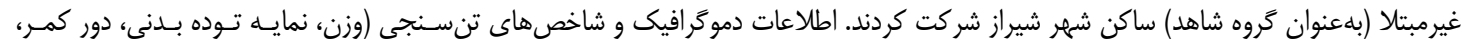

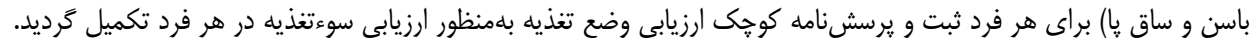

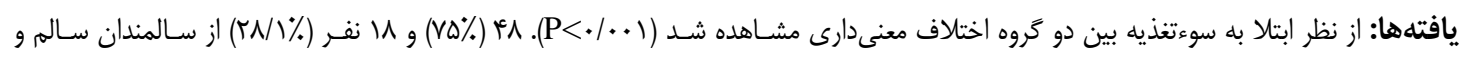

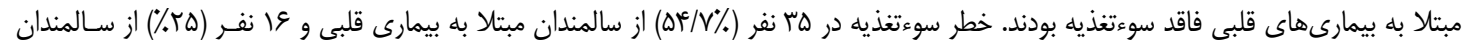

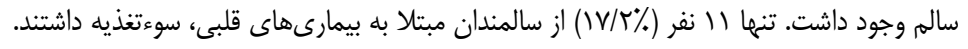

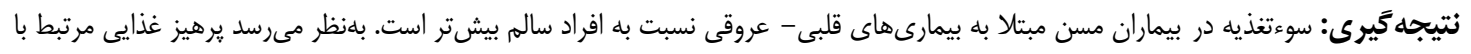

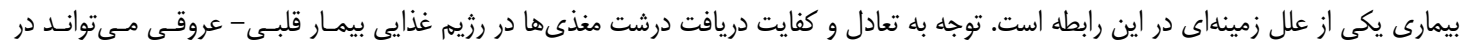
ييشخيرى از سوءتغذيه در دوره سالمندى مؤثر باشد.

كليدوازهها: سوءتغذيه، تنسنجى، سالمندى، بيمارىهاى قلبى - عروقى

بيمارىها شامل مى شوند.(r) بررسىها نشان داده كه يكى إنى

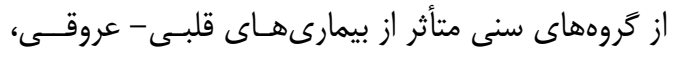

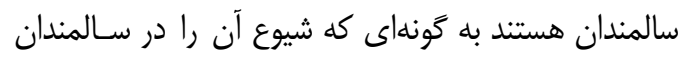

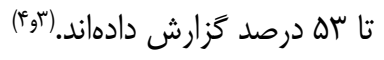

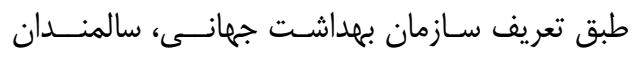

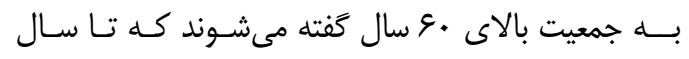

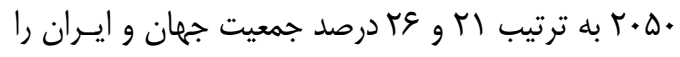

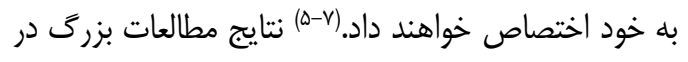

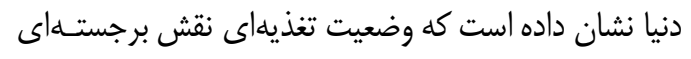

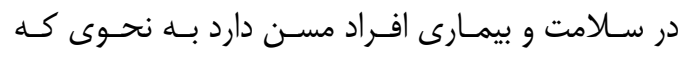

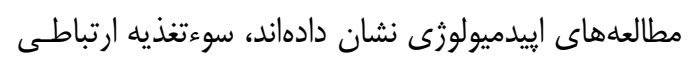

\section{潾}

بيمارىهاى قلبى - عروقى به گروهـى از اخـتلالات

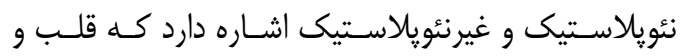

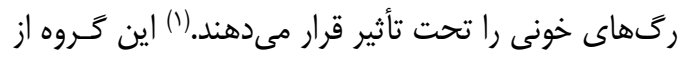

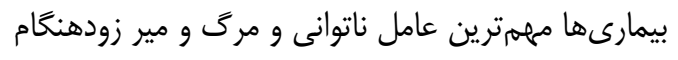

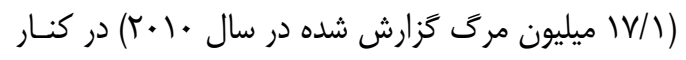

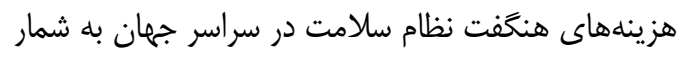

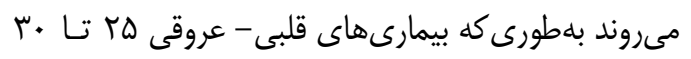

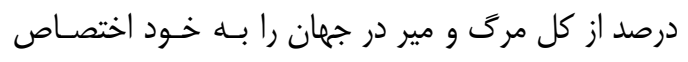

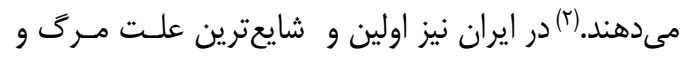

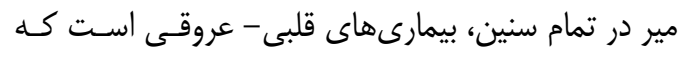

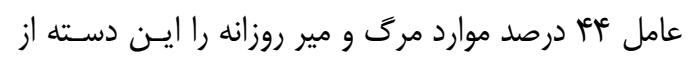


قلبى - عروقى با سالمندان غيرمبتلا در شهر شيراز انجـام كرديد.

\section{مواد و روشها:}

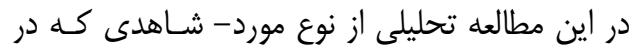

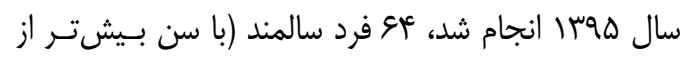

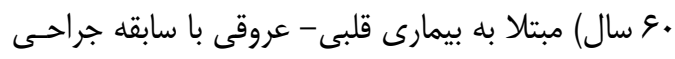

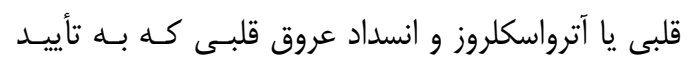
يزشك بالينى همكار در مركز بهداشتى - درمانى دانشـاه

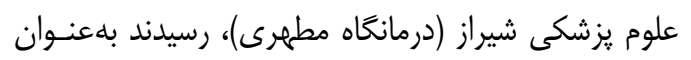

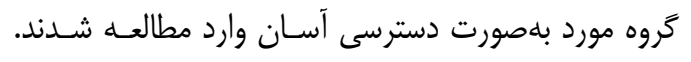

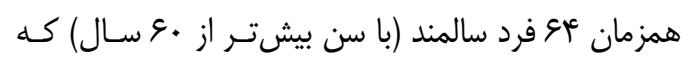

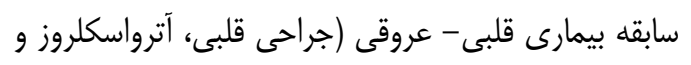

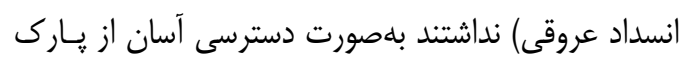

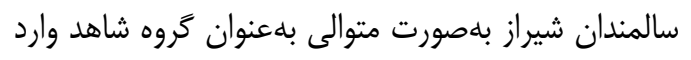

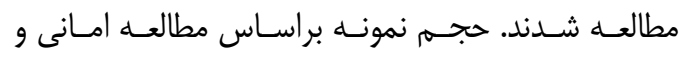

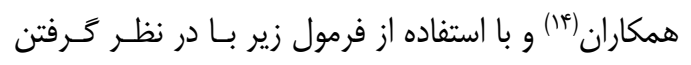
توان •م درصد و سطح معنىدارى هـ/ • تعيين كرديد. $x=\frac{\left(Z_{1-\frac{w}{\alpha}}+Z_{1-\rho}\right)^{2}\left(p_{1} q_{1}-v_{2} q_{2}\right)}{\left(\boldsymbol{\gamma}_{1}-\boldsymbol{F}_{2}\right)^{2}}$

از شرايط عدم ورود به مطالعه در هر دو گروه، ابتلاى

سالمند به بيمارى كليوى، كبدى، سرطان، ديابت، هر گونه بدخيمى و بيمارى احتقان قلبى بود. يِ إز شناسايى افراد

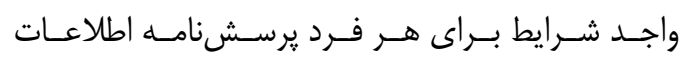

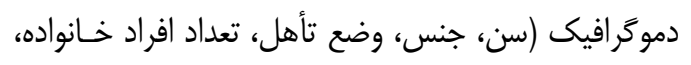

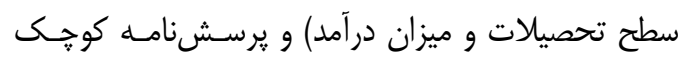

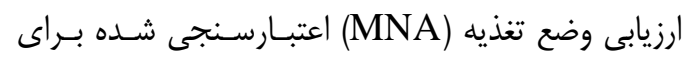

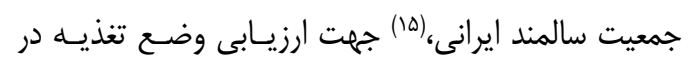

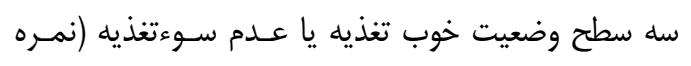

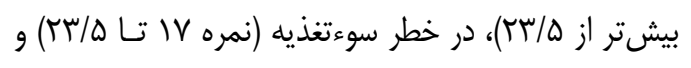

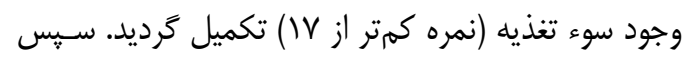
شاخصهاى تنسنجى شامل؛ وزن (با ترازوى سكا ساخت

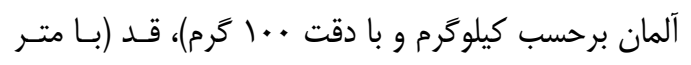
نوارى غيرقابل ارتجاع با دقت / / • سانتىمترك)، محيط دور
قوى با افزايش مرى و مير در افراد مسن دارد.(^) از سوى

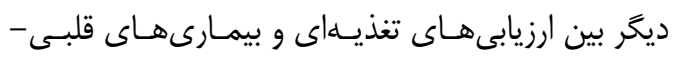

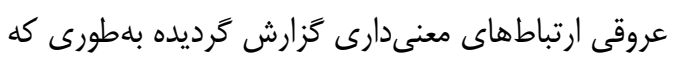

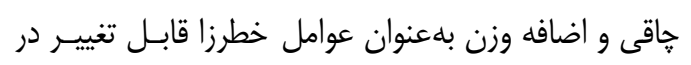

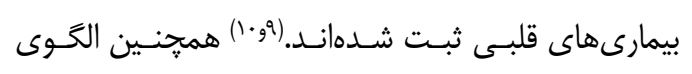
دريافت غذايى عاملى مهم در ابتلا به بيمارىهاى قلبـى فيسل

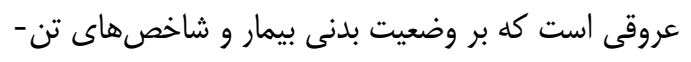

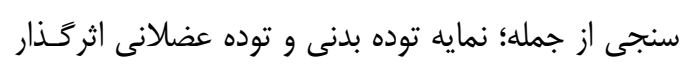

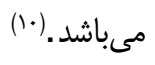
بررسىهاى انجام شده در بيماران همودياليزى، مبـتلا بودن به سوءتغذيه را از جملـه عوامـل مهـهم در ابـتلا بــهـ بيمارىهاى قلبى - عروقى اعلام كرده هرا كه ديده شـده

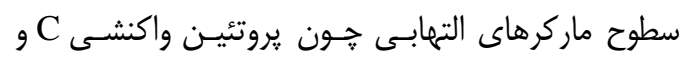

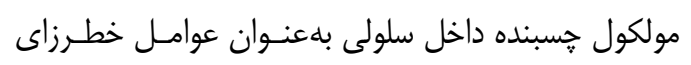

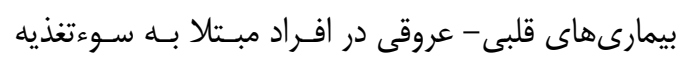

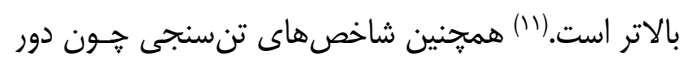

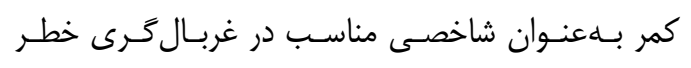

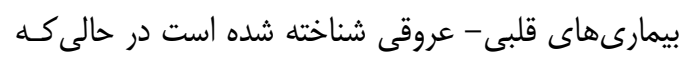

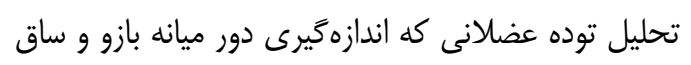
قا نمودى از آن است، هم در سالمندى و هـهم در بيمـاران

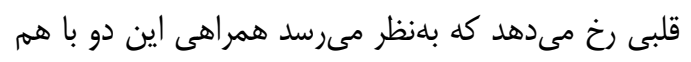

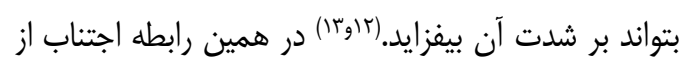

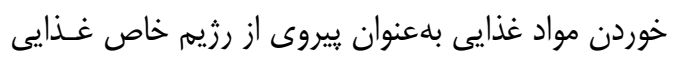

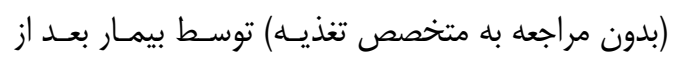

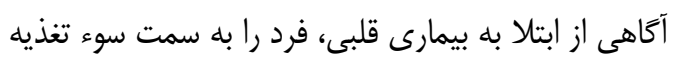

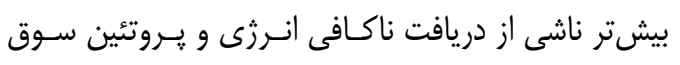
مى دهد. از آنجايى كه جمعيت زيادى از بيماران قلبى - عروقى

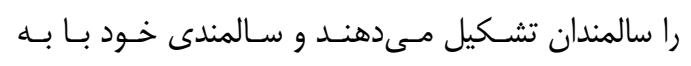
مخاطره افتادن وضعيت تغذيه و تحليـل عضــلانى همـراه

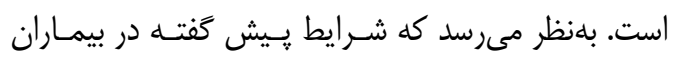

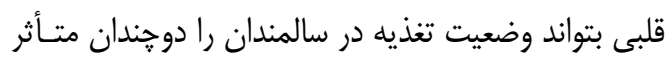

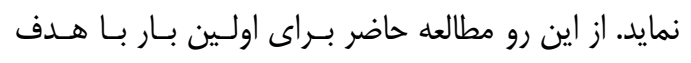

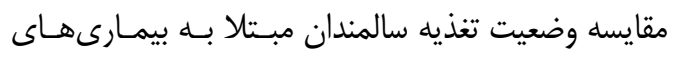


دو گروه استفاده گرديد. سطح معنى دارى كمتر از هـ/. در

نظر گرفته شد.

يافته ها:

بين افراد شركت كننده در دو گروها: از نظر سن، جنس،

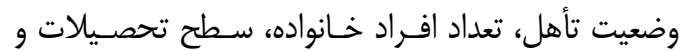

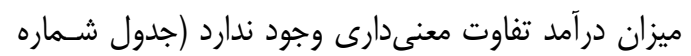

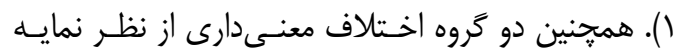

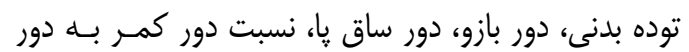

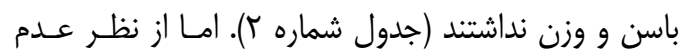

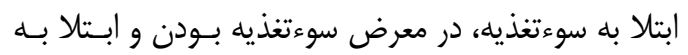

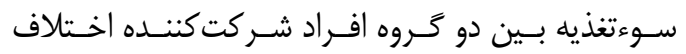

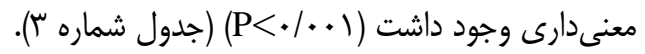

كمر (با متر نوارى قابل انعطاف با دقت / / • سانتىمتـر در

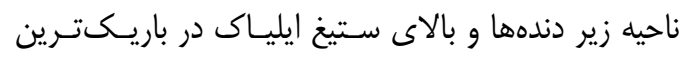

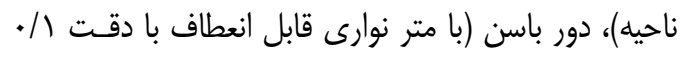

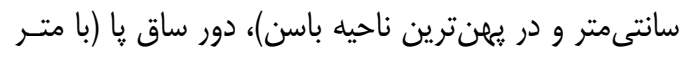

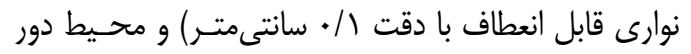

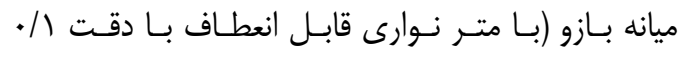

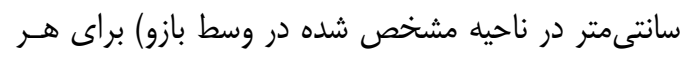

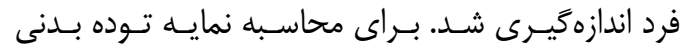

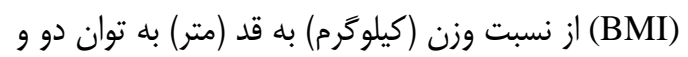

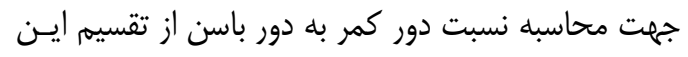

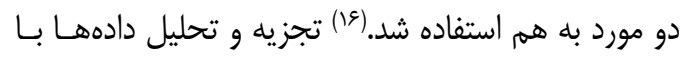

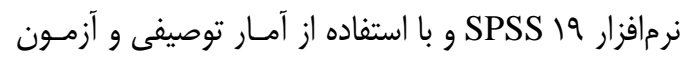

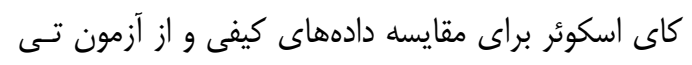

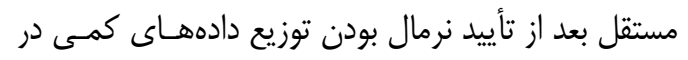

جدول ( - مقايسه اطلاعات پايه بين افراد مبتلاو غير مبتلا به بيمارىهاى قلبى - عروقى (در هر تروه عح نفر)

\begin{tabular}{|c|c|c|c|c|}
\hline سطح معنىدارى & افراد مسن سالم (كروه شاهـ) & افراد مسن مبتلا (كروه مورد) & \multicolumn{2}{|c|}{ اطلاعات جمعيتى } \\
\hline .199 & $\varepsilon N / F \pm V / F q$ & $\varepsilon q / \cdot \tau \pm V / r \Delta$ & \multicolumn{2}{|l|}{ سن (كيلوكَرم) } \\
\hline .1 .9 & $\Delta / \Lambda \pm r / r$ & $\varepsilon / \Delta \pm r / \Lambda$ & \multicolumn{2}{|c|}{ تعداد افراد خانواده } \\
\hline .109 & $\begin{array}{l}r \cdot(\mathscr{Q} V) \\
\mu F(\Delta r)\end{array}$ & $\begin{array}{l}\operatorname{TV}(\Psi Y) \\
\operatorname{TV}(\Delta \Lambda)\end{array}$ & مرن & $\xi$ \\
\hline . 194 & $\begin{array}{l}\Delta I(V Q / V) \\
\cdot \\
I(I / 9) \\
I T(I N / A)\end{array}$ & $\begin{array}{c}r q(V / q) \\
1(1 / q) \\
\cdot \\
\mid f(Y) / q)\end{array}$ & مجأه مجرد & 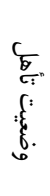 \\
\hline . & $\begin{array}{l}r(q / V) \\
r \cdot(r q / q) \\
r \phi(r q /)) \\
q\left(q / r^{q}\right)\end{array}$ & 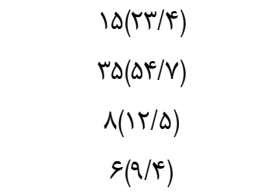 & 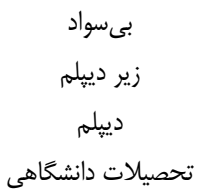 & 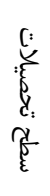 \\
\hline$\cdot|r|$ & 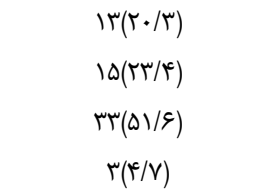 & $\begin{array}{l}19(r q / V) \\
19(r q / V) \\
r(r r / \Lambda) \\
\theta(Y / \Lambda)\end{array}$ & 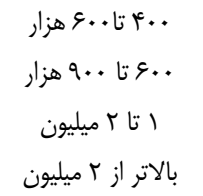 & 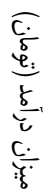 \\
\hline
\end{tabular}




\section{جدول r- مقايسه اندازهَيرىهاى تنسنجى و امتياز وضعيت تغذيه (MNA) بين افراد مبتلا و غيرمبتلا

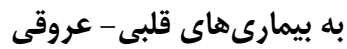

\begin{tabular}{|c|c|c|c|}
\hline \multirow{2}{*}{ سطح معنىدارى } & \multicolumn{2}{|c|}{ ميانگين 土 انحراف معيار } & \multirow{2}{*}{ شاخص } \\
\hline & افر اد مسن سالم & افراد مسن مبتلا & \\
\hline $.1 \cdot 1$ & $r E \pm Y / V$ & $\Gamma \in / V \pm \Gamma / \Delta$ & نمايه توده بدنى (كيلوكرم//مترمربع) \\
\hline.$/ 94$ & $r q / r \pm r / \Lambda$ & $r q / V \pm r / c$ & دور بازو (سانتىمتر) \\
\hline. $\mid 94$ & $r \varepsilon / 9 \pm r / r r$ & $r \varepsilon / \Delta \pm \psi / .9$ & دور ساق يا (سانتىمتر) \\
\hline$\cdot / \mathrm{NT}$ & $.198 \pm .1 .9$ & $\cdot / 9 \Delta \pm \cdot / \cdot V$ & نسبت دور كمر به دور باسن \\
\hline .199 & 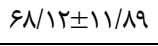 & $g V / \mu \pm I I / g r$ & وزن (كيلوكرم) \\
\hline
\end{tabular}

جدول سـ- مقايسه وضعيت تغذيه بين افر اد مبتلاو غيرمبتلا به بيمارى هاى قلبى - عروقى براساس برسشنامه

\begin{tabular}{|c|c|c|c|}
\hline سطح معنى دارى & (درصد) تعاد & بيماران قلبى & وضعيت تفذيهاى افراد مسن \\
\hline \multirow{3}{*}{$<\cdot 1 . .1$} & $\varphi(v \Delta)$ & $M(T N /)$ & عدم سوءتغذيه \\
\hline & $19(\Gamma \Delta)$ & $r \Delta(\Delta F / V)$ & در معرض سوءتنذيه \\
\hline & 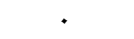 & $11(I V / \Gamma)$ & مبتلا به سوءتتذيه \\
\hline
\end{tabular}

\section{مبحث و نتيجلكيرى}

بيمارى با خود يرهيـزى و اولويـتبنـــى غـذايى در ايـن

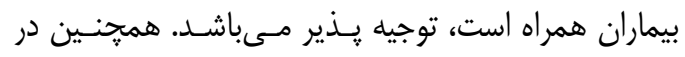

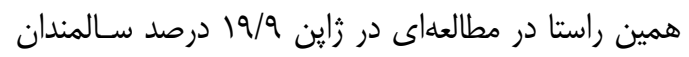

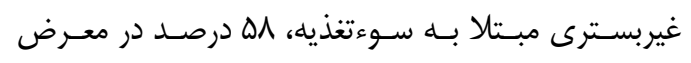

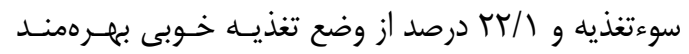

$$
\text { بودند. (1N) }
$$

در مطالعه حاضر ميانگين نمايه توده بـدنى سـالمندان سالم نسبت به بيماران قلبى بيشتر بود و از سـوى دئل ديخـر

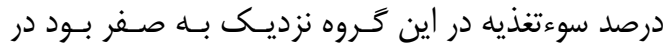

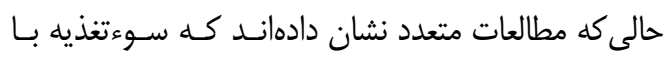

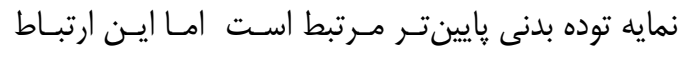

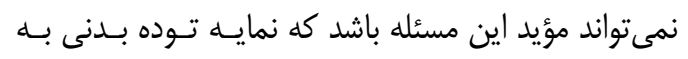

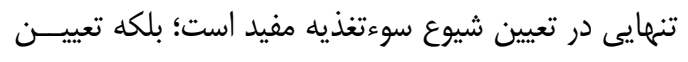

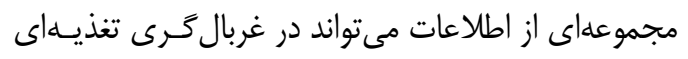

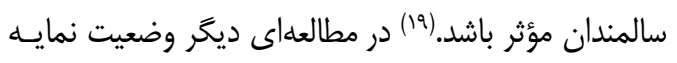

از آنجايى كه جمعيت زيادى از بيماران قلبى - عروقى تئى

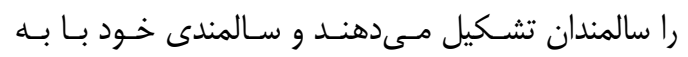

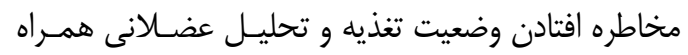

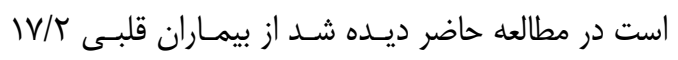

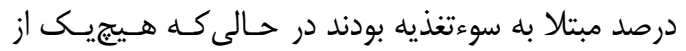
افراد گروه شاهد سوءتغذيه نداشتند. در اين مطالعه از ميان

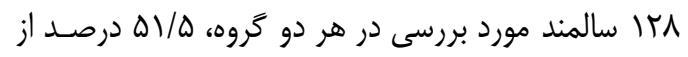
وضعيت تغذيهاى خوب،

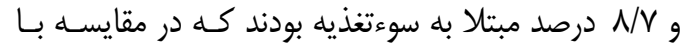

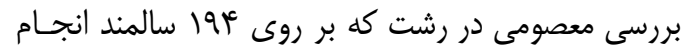

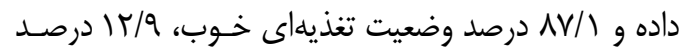

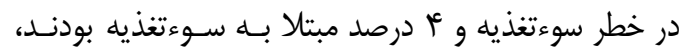

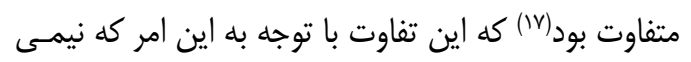

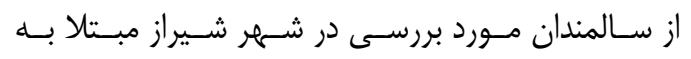

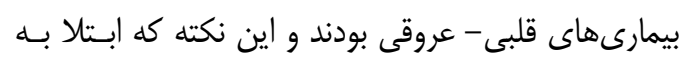


ميـانغخين سـنى، ميـزان درأمــــ و وضـعيت تأهـل تفـاوت

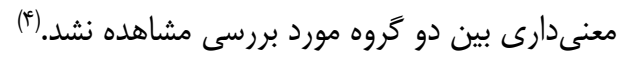

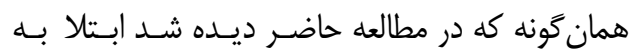
سوءتغذيه و در معرض سوءتغذيه بودن در گروه سـالمندان

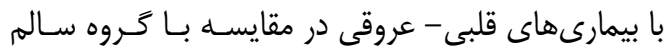

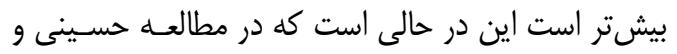

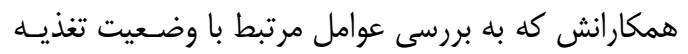
سالمندان مبتلا به نارسايى قلبى يرداختند، نتايج نشان داد

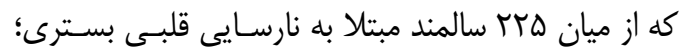

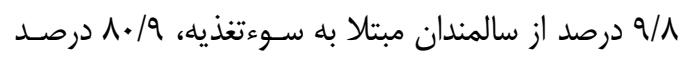

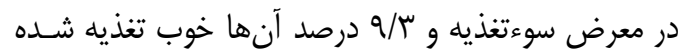

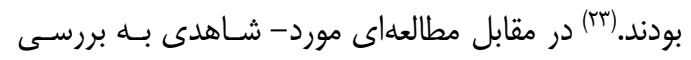

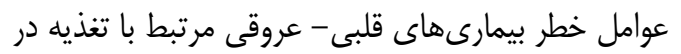

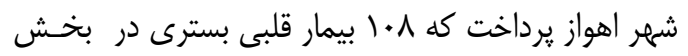

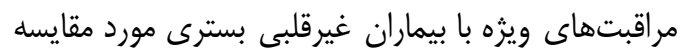

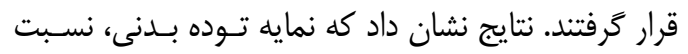

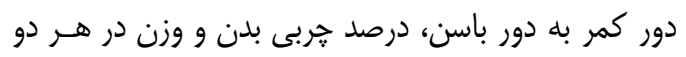

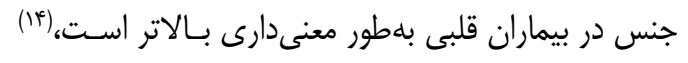

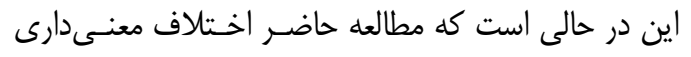
بين شاخصهاى تنسنجى در دو گروه نشان نــاد و تنهــا

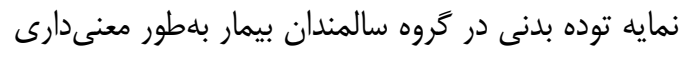

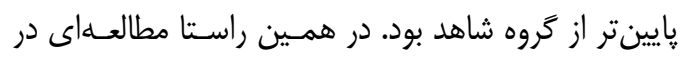
برزيل در بررسى وضعيت تغذيه سالمندان مشاهده كرد كه

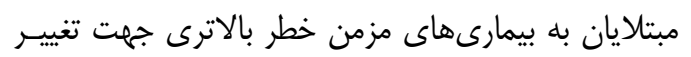

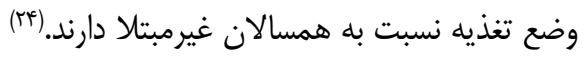

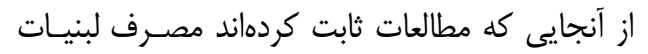

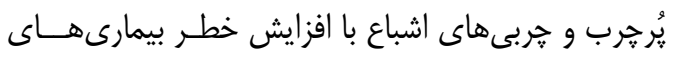

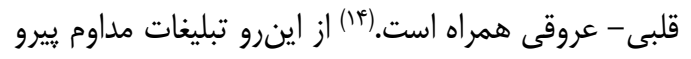

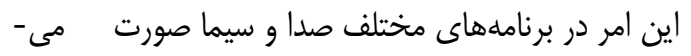
كيرد. از سوى ديخر يكى از معضلات ييش روى رئ بيمـاران

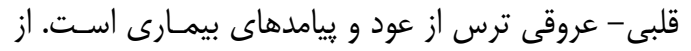

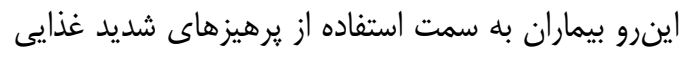

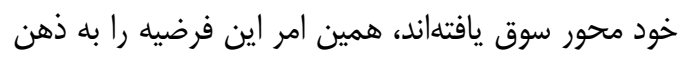

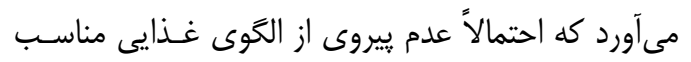

توده بـدنى ســالمندان شـهر اسـفراين در سـال 19 مـورد

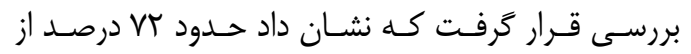

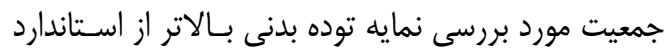

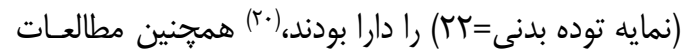

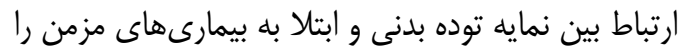

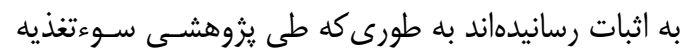

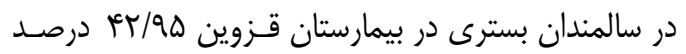

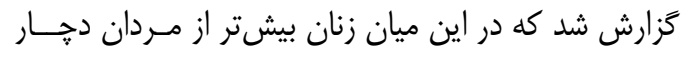

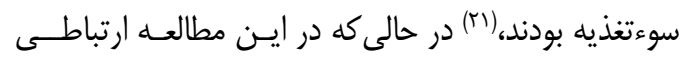

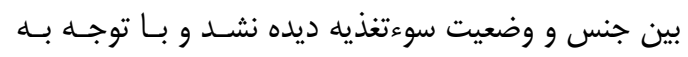

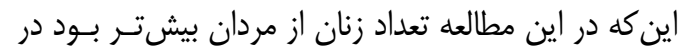
اين زمينه نمىتوان نتيجه درستى گزارش كرد.

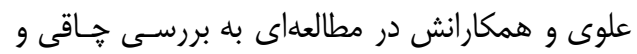
كم وزنى سالمندان و برخى عوامل مرتبط با بآن با استفاده داهي

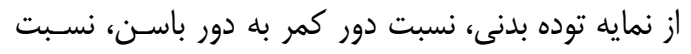

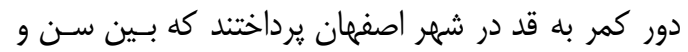

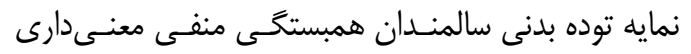

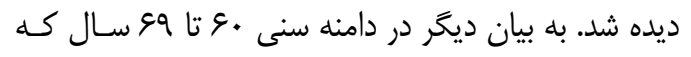

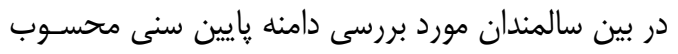

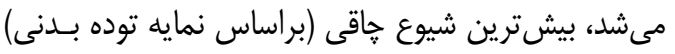

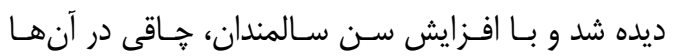

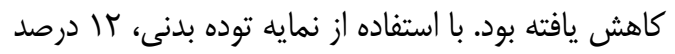

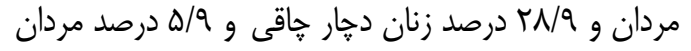

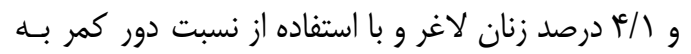

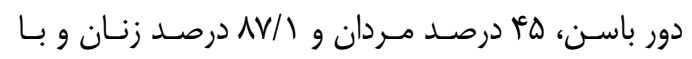

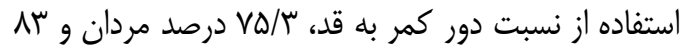

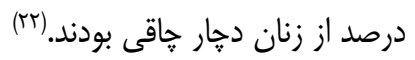

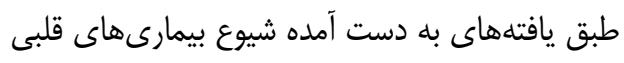
و فشارخون در سطح كشور به خصوص در بررسى انجـام شده در شهر ايلام بالا بـوده اسـت. شـيوع بيمـارىهـاى دئه مزمن در سالمندان با سن بالا، سطح سواد و مــدت زمـان

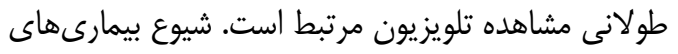

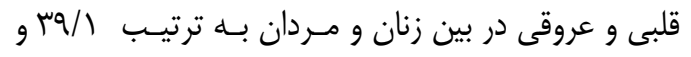

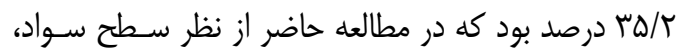


Circulation; 135(10): e146-603. doi: 10.11 61/CIR.000 0000000000485.

2. World Health Organization. Prevention of cardiovascular disease, guidelines for assessment and management of cardiovascular risk. 1st ed. Switzerland: World Health Organization; 2007. 2-3.

3. Hanna IR, Wenger NK. Secondary prevention of coronary heart disease in elderly patients. Am Fam Physician 2005; 71(12): 2289-96.

4. Peiman H, Yaghoubi $M$, Seyed Mohammadi A, Delpishe A. Prevalence of chronic diseases in the elderly in Ilam. Salmand Iranian J Age 2012; 6(4): 7-13. [In Persian]

5. Malek Afzali H, Baradaran Eftekhari M, Hejazi F, Khojasteh T, Tabrizi R, Faridi T. Social mobilization for health promotion in the elderly. Hakim Health Sys Res 2007; 9(4): 1-6. [In Persian]

6. Bandayrel K, Wong S. Systematic literature review of randomized control trials assessing the effectiveness of nutrition interventions in community- dwelling older adults. J Nutr Educ Behav 2011; 43(4): 25162. doi: 10.1016/j.jneb.2010.01.004.

7. Edmonds $\mathrm{P}$, Karlsen S, Khan S, Addington-Hall J. A comparison of the palliative care needs of patients dying from chronic respiratory diseases and lung cancer. Palliat Med 2001; 15(4): 287-95. doi: 10. 1191/026921601678320278.

8. Ulger Z, Halil M, Kalan I, Yavuz BB, CankurtaranM, Gungor E, Ariogul S. Comprehensive assessment of malnutrition risk and related factors in a large group of community-dwelling older adults. Clin Nutr 2010; 29(4): 507-11. doi: 10.1016/j.clnu. 2010.01.006.

9. Ozkara A, Turgut F, Kanbay M, Selcoki Y,
تحت نظر متخصص تغذيه منجر به دريافت ناكافى غذايى

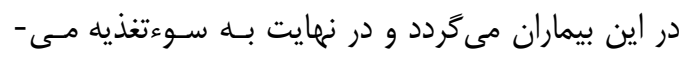

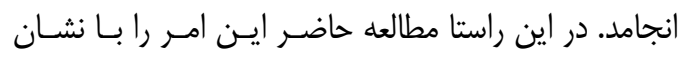

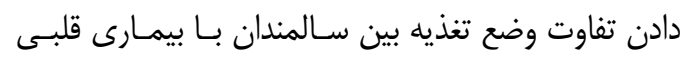

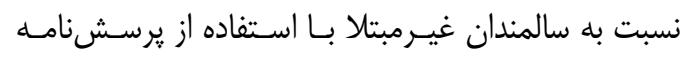

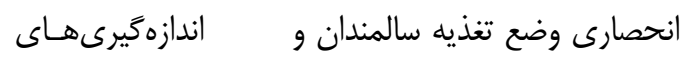

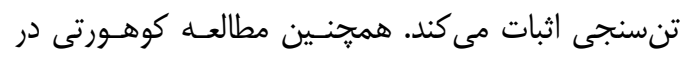

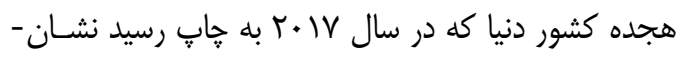

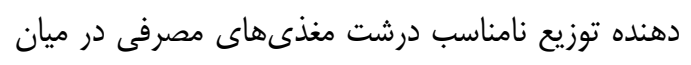

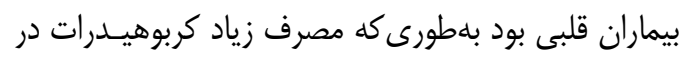
آنها خود عاملى در جهت افزايش خطر مرى و و ميـر ايسن

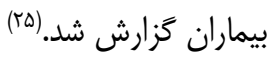
از نقاط ضعف مطالعه حاضر عدم ثبـت غـذايى افـراد

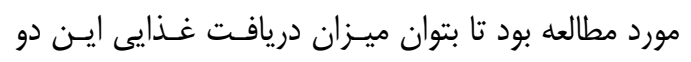

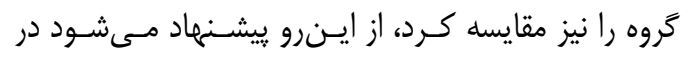

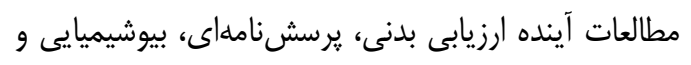

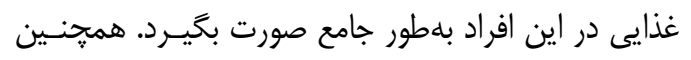

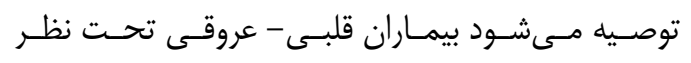

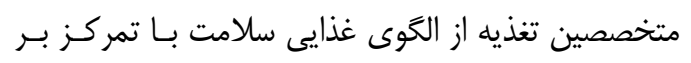
دريافت كافى انرزى و درشت مغذىها ييروى كنند تا مانع

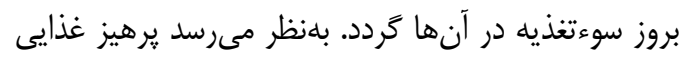
مرتبط با بيمارى يكى از علل زمينهاى در اين رابطه است.

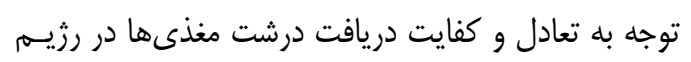
غذايى بيمـار قلبـى - عروقى مسىتوانـد در ييشـخيرى از سوءتغذيه در دوره سالمندى مؤثر باشد.

$$
\begin{aligned}
& \text { إن }
\end{aligned}
$$

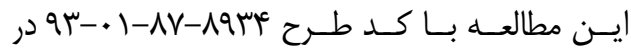

$$
\begin{aligned}
& \text { دانشگاه علوم يزشكى شيراز تصويب شده است. }
\end{aligned}
$$

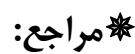

1. Benjamin EJ, Blaha MJ, Chiuve SE, Cushman M, Das SR, Deo R, et al. Heart disease and stroke statistics-2017 update: a report from the American Heart Association. 
Akcay A. Population-based cardiovascular risk factors in the elderly in Turkey: a crosssectional survey. Cent Eur J Med 2008; 3(2): 173-8. doi.org/10.2478/s11536-007-0058-7.

10. Sekuri C, Eser E, Akpinar G, Cakir H, Sitti I, Gulomur O, et al. Cardiovascular disease risk factors in post-menopausal women in West Anatolia. Jpn Heart J 2004; 45(1): 119-31.

11. As'habi A, Tabibi H, Hedayati M, Mahdavi-Mazdeh M, Nozari B. Association of energy-protein malnutrition with risk factors of cardiovascular diseases in hemodialysis patients. Iranian J Nutr Sci Food Technol 2011; 6(2): 43-54. [In Persian] 12. Baumgartner RN, Waters DL, Gallagher D, Morley JE, Garry PJ. Predictors of skeletal muscle mass in elderly men and women. Mech Ageing Dev 1999; 107(2): 123-36.

13. Kim Y, Wijndaele K, Lee DC, Sharp SJ, Wareham N, Brage S. Independent and joint associations of grip strength and adiposity with all-cause and cardiovascular disease mortality in 403,199 adults: the UK Biobank study. Am Clin Nutr 2017; 106(3): 773-82. doi: 10.3945/ajcn.117.156851.

14. Amani R, Noorizadeh M, Rahmanian S, Afzali N, Haghighizadeh MH. Nutritional related cardiovascular risk factors in patients with coronary artery disease in Iran: a casecontrol study. Nutr J 2010; 9: 70. doi: 10. 1186/1475-2891-9-70.

15. Malek Mahdavi A, Mahdavi R, Lotfipour M, Asghari Jafarabadi M, Faramarzi E. Evaluation of the Iranian mini nutritional assessment short-form in communitydwelling elderly. Health Promot Perspect 2015; 5(2): 98-103. doi: 10.15171/hpp. 2015.012 .

16. Laquatra I. Nutrition for Weight Management. Mahan LK, Scott-stump S.
Food, nutrition and diet therapy. 11th ed. Philadelphia: WB Saunders; 2004. 561-2.

17. Masomy N, Jefroodi SH, Ghanbari A, Kazemnejad E, Shojaei F, Rafiei AH. Nutritional status assessment and related factors in the retired senile. J Guilan Univ Med Sci 2012; 21(84): 65-70. [In Persian]

18. Kuzuya M, Kanda S, Koike T, Suzuki Y, Satake S, Iguchi A. Evaluation of mininutritional assessment for Japanese frail elderly. Nutrition 2005; 21(4):498-503. doi: 10.1016/j.nut.2004.08.023.

19. Coelho AK, Rocha FL, Fausto MA. Prevalence of undernutrition in elderly patients hospitalized in a geriatric unit in Belo Horizonte, MG, Brazil. Nutrition 2006; 22(10): 1005-11. doi: 10.1016/j.nut. 2006.07.001.

20. Mollazadeh T, Honarbakhsh AR. Evaluating BMI status in Esfarayen elderly people. First National Conference on Applied Research in Public Health and Sustainable Development. 2013 Sep; Shirvan: 1(1): 91 [In Persian]

21. Ghorbani A, Karimzadeh T, Azadmanesh Y. Nutritional Assessment in Elderly Hospitalized Patients in Qazvin Teaching Hospitals in 2011. Salmand Iranian J Age 2013; 8(1): 33-40. [In Persian]

22. Âlavi naeini AM, Dorosty motlagh AR, Âghdak P. Survey of obesity, underweight and associated factors in elderly people, using some of anthropometric indices in Isfahan city, 2004. J Mazandaran Univ Med Sci 2006; 16(52): 117-25. [In Persian]

23. Hosseini S, Keshavarz A, Amin A, Maleki M, Bakhshandeh Abkenar H. Nutritional status and non-diet associated factors of hospitalized heart-failure elderly patients. Salmand Iran J Ageing 2010; 5(2): 61-6. [In Persian] 
24. Campos MA, Pedroso ER, Lamounier JA, Colosimo EA, Abrantes MM. Nutritional status and related factors among elderly Brazilians. Rev Assoc Med Bras (1992) 2006; 52(4): 214-21. doi.org/10.1590/S010442302006000400019 .
25. Dehghan $\mathrm{M}$, Mente A, Zhang $\mathrm{X}$, Swaminathan S, Li W, Mohan V, et al. Associations of fats and carbohydrate intake with cardiovascular disease and mortality in 18 countries from five continents (PURE): a prospective cohort study. Lancet 2017g; 390(10107): 2050-62. doi.org/10.1016/ S0140-6736(17)32252-3. 